\title{
GESTÃO POR PROCESSOS EM UMA UNIDADE ADMINISTRATIVA MILITAR
}

\author{
MANAGEMENT BY PROCESSES IN A MILITARY ADMINISTRATIVE UNIT
}

\author{
Recebido em 04.03.2019 Aprovado em 17.12.2019 \\ Avaliado pelo sistema double blind review \\ DOI: https://doi.org/10.32888/cge.v7i2.28193
}

\author{
Rafael Rodrigues Bastos Pontes \\ rrbpontes@uol.com.br \\ Mestrado em Desenvolvimento Regional/Centro Universitário Alves Faria - Goiânia, Goiás, Brasil \\ Paulo César Bontempo \\ pcbontempo@gmail.com \\ Mestrado em Desenvolvimento Regional/Centro Universitário Alves Faria - Goiânia, Goiás, Brasil
}

\section{Resumo}

O setor de aquisições é um departamento importante quando se estuda a gestão das organizações, sejam elas públicas ou privadas. Dentro deste tema, a gestão por processos tem alcançado uma grande relevância, levando-se em conta sua possibilidade de aplicação ao cotidiano das instituições. Baseandose nisso, este trabalho teve como objetivo identificar oportunidades de melhoria no processo de compras de uma unidade administrativa militar, fazendo um diagnóstico da situação atual, através da análise e apresentação dos resultados obtidos pela organização na pesquisa foi realizada. Com a contribuição esperada da implementação do modelo de gestão por processos na unidade administrativa, é proposto, sob forma de assessoramento, um novo mapa para as compras que vem sendo realizadas pela organização. A análise se dá por meio da percepção de pessoas de diferentes níveis hierárquicos dentro da organização, mediante uma entrevista semiestruturada e um questionário baseado na escala Likert. Foi feita também uma análise SWOT a partir dos dados obtidos, buscandose elementos para um redesenho de processos e um trabalho de mapeamento das atividades realizadas, no qual pudessem ser atribuídos novos papéis e responsabilidades aos envolvidos.

Palavras-chave: Gestão por processos; aquisições; oportunidade de melhoria.

\begin{abstract}
The procurement sector is an important department when studying the management of organizations, be they public or private. Within this theme, the management by processes has reached a great relevance, taking into account its possibility of application to the daily life of the institutions. Based on this, this work aimed to identify opportunities for improvement in the procurement process of a military administrative unit, making a diagnosis of the current situation, through the analysis and presentation of the results obtained by the organization in the research was carried out. With the expected contribution of the implementation of the process management model in the administrative unit, a new map for the purchases being made by the organization is proposed in the form of advice. The analysis takes place through the perception of people of different hierarchical levels within the organization, through a semi-structured interview and a questionnaire based on the Likert scale. A SWOT analysis was also made based on the data obtained, searching for elements for a redesign of processes and a mapping of the activities carried out, in which new roles and responsibilities could be assigned to those involved.
\end{abstract}

Keywords: Process management; acquisitions; improvement opportunity. 


\section{Introdução}

Mesmo a organização sendo privada ou pública, sendo empresa de grande porte ou microempresa, possuindo ou não fins lucrativos, isso se torna irrelevante à medida que a finalidade principal de uma organização é a geração de valor tanto para seus clientes internos quanto externos através dos seus produtos e serviços desenvolvidos (BPM CBOK 2013).

O processo de compra, normalmente faz parte da atividade-meio das organizações, também deve possuir uma atuação finalística devido às suas múltiplas funções e seu valor estratégico dentro da mesma. Considerando sua capilaridade e interação organizacional, o referido processo deve ser visto de forma interdepartamental, sendo impactado por diversos fatores, tornando-se fundamental a operacionalização das suas atividades (TERRA, 2016). Mas mesmo levando-se em conta a complexidade que envolve a gestão de compras, a área possui grandes desafios, assim como grandes oportunidades de crescimento.

Por experiências presenciadas por este pesquisador foi percebido a dinâmica do assunto ao longo do tempo, onde as pessoas envolvidas nos vários processos que cercam a gestão de compras têm o dever de seguir e ter conhecimento e atualizações sobre o assunto. Porém, diante das circunstâncias que ocorrem na prática, é realmente isso o que vem acontecendo? A organização objeto de estudo está disposta a realizar as mudanças ou adaptações necessárias? O pessoal que participa dos processos de compras na organização militar está apto e desenvolvendo da melhor maneira o que se espera deles?

Apesar da relevância do tema e da necessidade de se gerir da melhor forma os recursos repassados, não é comum no meio, que organizações adotem sistemas de avaliação e indicadores de desempenho que visem conhecer o grau de eficiência dos processos de compras, tornando-os, muitas vezes, desconhecedores do grau em que se encontram na atual conjuntura. Em virtude deste descompasso, surge a questão problema desta pesquisa: como proporcionar melhorias no processo de aquisições dentro de uma organização administrativa militar, adaptando a atividade para se adequar aos mais modernos desafios e aplicando as melhorias necessárias, assim como, identificar as novas oportunidades que se apresentam dentro da administração?

A resposta a esta questão é não é simples, complexa e passa pelo por uma pesquisa de campo realizada dentro da organização com o intuito de alcançar o objetivo geral estabelecido: identificar oportunidades de melhoria no processo de compras de uma unidade administrativa militar, através da análise e apresentação dos resultados obtidos pela organização no trabalho desenvolvido.

Para atingir tal objetivo aqui proposto foi necessário satisfazer aos seguintes objetivos específicos: diagnosticar em que situação se encontra o processo de aquisição na organização militar no momento; levantar com o pessoal envolvido no processo de compra os mais importantes fatores que podem contribuir para a melhoria da função; e propor melhorias no processo de aquisições da unidade objeto do presente estudo.

A atualidade deste tema, assim como o cenário de austeridade; economicidade; probidade administrativa e transparência nos processos; bem como as potenciais contribuições do trabalho para o meio e para gestores, justificam a realização da pesquisa e o torna relevante na medida em que, segundo Oliveira (2007), a gestão por processos realizada de maneira eficiente ajuda a alavancar a capacidade de antecipação, a forma como gerir contingências e dar uma resposta rápida frente às mudanças num contexto de mercado dinâmico, de maneira que quando adequadamente empregada, pode ajudar na redução das insuficiências e de possíveis erros em função de uma redundância de informações desnecessárias e ações institucionais. 


\section{Referencial Teórico}

\section{Gestão Por Processos}

De acordo com Raducnizer (2008) a fundamentação da gestão por processos é importante tanto para a definição, quanto para a compreensão de quais são os processos mais relevantes para a organização, bem como aqueles que estão em condições de suportá-los. Desta forma, ao se juntar uma visão estratégica ao conhecimento sobre gestão por processos será possível a construção de um Mapa Geral de Processos da empresa.

Sob a ótica de gestão por processos, a instituição deve objetivar a mudança na forma de pensar, deixando de lado a visão de estrutura por funções, e planificar seus recursos e fluxos no decorrer de seus processos basilares de operação. A organização com a orientação voltada a processos pressupõe que as pessoas executem seu trabalho de forma diferente; ao invés do trabalho individual e focado nas tarefas, a organização por processos reconhece a responsabilidade individual, a cooperação, o trabalho em equipe, e a vontade de se fazer um melhor trabalho (VINHEIROS, 2008).

Por meio da gestão por processos pode-se ter uma visão panorâmica da organização e de seus processos, bem como de suas respectivas relações. Alguns componentes são relevantes para seu desenvolvimento, tais como: a adequação de ferramentas tecnológicas; o dimensionamento do tamanho ideal da equipe para a execução dos processos; os procedimentos de controle e monitoramento do desempenho a serem aproveitados e o nível de integração e interdependência dos processos. Colocar esta modalidade de gestão em prática requer uma nova visão de analisar e decidir como será o dia-a-dia da instituição de hoje e em seu futuro (RADUCNIZER, 2008).

Entretanto, ao buscar estruturarem-se por processos, as organizações acabam se deparando com a dificuldade de sobrepor um processo integrado a uma instituição fragmentada pela clássica estrutura funcional (HAMMER e STANTON, 1999). Empresas estruturadas por tarefas necessitam ser redesenhadas para poder funcionar por processos. Algumas organizações acabam dando alguns passos e logo desistem, sem saber ao certo como dar continuidade e levar em diante a transição.

\section{Organograma e Processos}

Os organogramas não são adequados para o diagnóstico dos processos de negócio, uma vez que não revelam como eles funcionam na prática nem como acontecem o fluxo de processos na empresa. Os processos de negócio estão pautados com o funcionamento da organização e, via de regra, não se limitam ao que é colocado pelos organogramas.

A empresa estruturada por processos pode ter o aspecto de uma estrutura funcional, com áreas bem definidas, entretanto com processos circulando efetivamente de forma horizontal. Não se tratando de uma estrutura matricial, mesmo existindo relações de dupla subordinação nas organizações estruturadas por processos. Frequentemente as mesmas pessoas envolvidas participam efetivamente de vários processos simultaneamente (GONÇALVES, 2000).

Ainda segundo este mesmo autor, na realidade, as áreas funcionais e seus chefes não desaparecem quando a empresa opta pela mudança, estruturando-se por processos. À medida que os process owners ("donos do processo") vão adquirindo uma responsabilidade crescente pelo projeto, pela estruturação e pelo funcionamento dos processos essenciais das organizações, as chefias das áreas funcionais estão voltadas, cada vez mais, no treinamento e desenvolvimento dos todos os envolvidos.

Entretanto, os process owners não são chefes dos empregados que atuam nos seus processos, eles não podem dar ordens, liderando através da negociação e influência pelo conhecimento. Para a implementação, não pode ser baseada em controle rígido e comando: necessita-se de colaboração e negociação (Hammer e Stanton, 1999). Todos os envolvidos necessitam aprender e se adequar a trabalhar em ambientes de mútua colaboração. 


\section{Organizar por Processos}

As estruturas organizacionais tradicionais apresentam algumas características indesejáveis que influenciam negativamente o desempenho das organizações: elas priorizam as funções em detrimento dos processos essenciais e exageram na divisão de tarefas, levando à hiperespecialização (GONÇALVES 2000).

Nesse contexto, as organizações apresentam estruturas hierárquicas inflexíveis, pesadas e rígidas, compostas por "caixinhas" que executam partes fragmentados de processos de trabalho. Em cada "caixinha", prevalecem atividades padronizadas, compostas por vários níveis de chefia, sendo a finalidade precípua a garantia do cumprimento das normas pré-estabelecidas (Gonçalves e Dreyfuss, 1995).

A gestão por processos se distingue da gestão por funções clássica em, no mínimo, três pontos: as pessoas e recursos são agrupados gerando um trabalho completo; traça objetivos externos; e o fluxo das informações seguem diretamente para onde é necessária, sem os entraves causados pelo excesso da hierarquia (Stewart, 1992). Logo, o sucesso para a implementação da gestão por processos está diretamente ligado ao esforço de diminuir a subdivisão dos processos organizacionais.

A abordagem horizontal das organizações é uma forma de identificação e aperfeiçoamento das interfaces funcionais, que são os pontos de partida nos quais o trabalho que está sendo desenvolvido é transferido de uma unidade organizacional para a seguinte (Gonçalves 2000). São nessas transferências que acontecem os maiores erros e desperdícios de tempo, sendo responsáveis por grande parte da diferença entre o tempo de ciclo e o tempo de processamento nos processos organizacionais. A organização terá melhor proveito dos conhecimentos adquiridos em todas as áreas quando for capaz de compartilhá-los e transferi-los dentro de um fluxo horizontal de conhecimento.

\section{Mapeamento de Processos}

Partindo como critério de limitação ao campo da pesquisa, a etapa de mapeamento do processo existente, abordará o processo de compras e os fatores influenciadores sobre essa fase, além de suas implicações ao projeto inicial. Visto que em cada fase do processo, existe a possibilidade de fatores obstrutores, deixando a pesquisa extremamente extensa e de difícil aplicação.

De acordo com Pinho, Leal e Almeida (2006), o mapeamento tem como finalidade principal levar o pesquisador à percepção dos processos de forma visual e prática, sendo considerado tanto uma ferramenta gerencial quanto uma ferramenta de comunicação, tendo como objetivo auxiliar a melhorados processos existentes ou até ajudar na implantação de uma nova estrutura. Esta ferramenta fornece uma abordagem de forma que processos complexos sejam avaliados de uma forma mais simples, fazendo com que a equipe possa ter uma visão integral do processo.

O processo de mapeamento identifica falhas, podendo ser em equipamentos ou ser falha humana, ambas ocasionando grandes perdas econômicas, além de comprometer a imagem da instituição perante a sociedade, devendo este processo ser o mais transparente possível e com responsabilização dos envolvidos. Isto reforça a necessidade de se estudar aspectos relacionados ao assunto, objetivando a sua prevenção. É essencial que as organizações se conscientizem de que, mais importante do que encontrar um culpado pela falha, será a análise do que levou ao acontecimento e à tomada de decisão - para evitar que estes se repitam. Este conceito é chamado de "falha como oportunidade". Portanto, evidencia uma importante consideração, levando-se em conta que nenhuma organização está isenta de deficiências (ALMEIDA e FAGUNDES, 2005).

\section{Gerenciamento de Processos de Negócio}

A ideia para a solução aos problemas de gestão, abordada pela metodologia do Gerenciamento de Processos de Negócio, do inglês Business Process Management (BPM) envolve cada vez mais pessoas entusiastas desta excelente técnica. Tendo como elemento central de sua implementação e para quem 
serão gerados seus valores: o cliente. Sendo um "conjunto de atividades com uma ou mais espécies de entrada que cria uma saída de valor para o cliente.” (HAMMER; CHAMPY, 1994)

2.3.1 Geração de valor para o cliente (Setor Privado e Público)

Segundo Silva (2014), temos embasamentos que nos evidenciam as causas pelos quais a ferramenta BPM vem sendo amplamente utilizada, trazendo a proposta de conferir maior agilidade, flexibilidade e respostas rápidas e eficazes às demandas das organizações. Estas causas têm feito com que várias organizações, sejam elas do setor público ou privado, que buscam um cenário de mudança, cheguem à conclusão de que a proposta disseminada na abordagem sugerida pelo modelo de gerenciamento de processos atende às suas expectativas.

De acordo com Dinsmore (2009) a gestão por processo consiste na criação de uma nova cultura, trazendo uma forma inovadora de como a organização é vista e gerenciada. Estes mesmos autores nos trazem a seguinte definição: "é uma forma de organizar a estrutura da entidade, realocando os recursos disponíveis nas áreas priorizadas pelas metas da instituição de forma a melhorar o desempenho de cada uma, o que gera um alinhamento entre os processos da organização e suas estratégias".

Porém, ao atribuir à técnica BPM como sendo apenas um processo de melhoria seria diminuir demais a sua dimensão. A referida ferramenta deve ser pensada como uma técnica de transformação de processos, pois a transformação obtida supera-se, indo além do que apenas a melhoria, havendo também a ruptura de paradigmas, mudanças e inovações. Transformar significa ser líder e obter novas formas de geração de valor para a sociedade assim como para os clientes (BPM CBOK, 2013).

\section{A implantação do gerenciamento por processos: papéis e responsabilidades}

A transformação de uma organização tradicional para uma orientada por processos acarreta a mudança para funções especializadas, e a necessidade de se lançar novas responsabilidades e atribuições dentro da organização. Introduzir a gestão em BPM gera novos papéis, tais como: nova distribuição de tarefas, redução nos gastos excedentes, e implica também em desagradar pessoas que exerciam anteriormente funções dispensáveis à cadeia de valor (SILVA, 2014).

De acordo com este autor ainda, a abordagem em organizações públicas deve ser tratado de forma diferente, então, a mudança, a movimentação e a atribuição de novas funções aos servidores, é peculiar devido as mais variadas formas de ingresso permitida, o meio e a forma empregada para que se possa comprar, a maneira como se define a distribuição dos cargos e salários, a diferença de parte do corpo de servidores ter estabilidade e outros não, a capacitação do pessoal envolvido, a forma de hierarquização das atribuições, as regulamentações que cercam todo o quadro de servidores públicos, acarreta em um panorama bem diferente do que acontece na iniciativa privada.

Desta forma, todas essas colocações transcendem bastante a realidade no momento no que diz respeito ao nível de amadurecimento de grande parte das organizações públicas, posto que torna o estágio de desenho ideal, um desafio a ser implementado, além de serem um ponto importante dentro da particularidade de cada organização e do panorama atual das organizações públicas.

\section{Metodologia da Pesquisa}

Caracterizada como empírica e sob o aspecto da abordagem qualitativa e quantitativa, a pesquisa realizada, preocupou-se fundamentalmente com o bases em experiências em seu ambiente normal de trabalho, assim a presença do pesquisador foi fundamental no processo de coleta e análise dos dados, ficando este responsável por analisar, observar, selecionar e registrar as informações pesquisadas, não sendo adequada a delegação destas atribuições que demandam ao pesquisador algumas habilidades especificas, tais como: capacidade para ouvir; observar o ambiente que o rodeia; organização para registro dos fatos; abertura e flexibilidade; e capacidade de interação com o grupo de investigadores e com os agentes envolvidos na presente pesquisa (GIL, 2008).

Visando atingir os objetivos gerais e específicos, a presente pesquisa pode ser caracterizada 
como descritiva, contendo dados quantitativos e qualitativos, tendo sido avaliada as opiniões dos funcionários pertencentes a seção de aquisições, licitações e contratos de uma organização militar, além de um participante externo, de uma outra unidade que elabora os pedidos e requisições para a seção que é a principal para o estudo, totalizando dez entrevistados para o trabalho.

A Pesquisa descritiva é aquela que busca conhecer e evidenciar características de determinada população ou fenômeno, bem como estabelecer correlações entre variáveis, contribuindo com a definição da natureza do que é estudado (VERGARA, 2014).

Os dados foram levantados por meio da pesquisa de campo através da aplicação de entrevistas semiestruturadas com o intuito de analisar o comprometimento dos funcionários e o grau de participação e expectativa quanto à adaptação da organização para a transição, passando a ser orientada por processos, assim como a verificação de oportunidades de melhoria. Foram sete perguntas que foram feitas de forma individualizada, cujo o local foi dentro da própria organização.

Outra forma de serem levantados os dados, foi através da utilização de um questionário contendo dez perguntas fechadas, sendo elas balizadas pela aplicação da escala Likert, complementando as perguntas abertas da entrevista semiestruturada, relacionando o tema com as expectativas dos funcionários para a transição quanto a movimentação dos processos. O questionário foi aplicado às mesmas pessoas entrevistadas com a utilização do questionário semiestruturado, sendo dividido em três blocos, nos seguintes assuntos: mapeamento dos processos, redesenho dos processos e adaptações na estrutura da organização, sendo todos os blocos buscando a viabilização da gestão por processos.

\section{Estudo de caso}

Para o autor YIN (2005), o estudo de caso é uma estratégia de pesquisa que pode ser aplicada quando o pesquisador possui pouco controle sobre os eventos comportamentais e investiga um fenômeno contemporâneo dentro de seu contexto real.

No desenvolvimento de uma pesquisa empregando o método do estudo de caso faz- se necessário o cumprimento de cinco etapas, que são elas: o delineamento da pesquisa; a definição do caso; a observação e coleta dos dados; análise e triangulação dos dados e a conclusão YIN (2005).

\section{Roteiro de entrevista semiestruturada}

Segundo Manzini (1991), a entrevista semiestruturada mantém seu foco diante de um assunto sobre o qual confecciona-se um roteiro com as questões principais, que devem ser complementadas por outras perguntas próprias para as circunstâncias de momento durante a realização da entrevista, pois pode fazer emergir informações importantes de maneira mais livre, de forma que as respostas não ficam condicionadas a um padrão de alternativas.

Sendo assim, a pesquisa foi realizada no âmbito de uma unidade militar que tem como principal característica a realização de atividades administrativas, englobando a atividade de aquisições e outras áreas correlatas na Administração, tendo sido conduzida inicialmente através de uma entrevista semiestruturada, por meio de um roteiro proposto com questões que serão aplicadas aos servidores envolvidos. Com as entrevistas, buscou-se identificar questões do perfil profissional, tais como tempo na instituição, atividades realizadas, suas responsabilidades e atribuições, assim como seções com as quais se tem mais interação. Para isso, foram entrevistadas dez pessoas, dos seguintes departamentos: seção de aquisições e contratos; seção de licitações; seção de conformidade de registro e gestão; além de um militar de outra organização que é o principal requisitante para compra de material e prestação de serviço.

Desta forma, foram abordados militares de diferentes níveis hierárquicos em busca de um amplo campo de visão sobre o processo, obtendo-se diferentes opiniões que poderão contribuir para a melhoria. Na sequência, foi abordado o levantamento de questões estratégicas da organização, referentes aos objetivos gerais e específicos propostos no trabalho e referenciados nas teorias 
abordadas sobre a gestão por processos, gestão de aquisições, com o objetivo de se conhecer o perfil das atividades de compras da organização, conhecendo seus pontos fortes e buscando agir corretivamente nos pontos fracos encontrados, assim como fatores de oportunidades ou ameaças na busca de sugestões de melhoria para a instituição.

As sete perguntas que foram formuladas de modo a atender os propósitos da pesquisa:

1. Qual a função ocupada na Organização Militar, tempo de serviço e atividades desenvolvidas?

2. A quantidade de servidores que a organização possui no setor de aquisições é adequado?

3. A gestão de aquisições tem atendido da melhor forma as demandas das organizações que estão vinculadas administrativamente? Caso a resposta seja negativa, onde considera que temos uma oportunidade de melhoria?

4. Quais as modalidades de licitação que são utilizadas?

5. Quais as falhas existentes no setor de aquisições e o que poderiam ser melhoradas? Dê sugestões para que tenhamos essa melhoria.

6. Você acha que uma mudança na forma como são conduzidos os processos intraorganizacionais seria possível e efetivamente aplicável na instituição? Você estaria disposto a aceitar e participar dessa mudança?

7. Você se sentiria mais valorizado e reconhecido pela instituição ao fazer parte dessa mudança mesmo tendo mais responsabilidade?

\section{Questionário baseado na Escala Likert}

A escala Likert utilizada neste estudo possui cinco notas correspondentes à opinião do entrevistado sobre as afirmações. Desta forma, as notas variam de 1 a 5 , compondo um intervalo correspondente a 1 indica discordo totalmente, 2 indica discordo parcialmente, 3 indica indiferença, 4 indica concordo parcialmente e 5 indica concordo totalmente. A referida escala possui como vantagem a facilidade de aplicação do questionário na organização, posto que a metodologia é assimilada rapidamente pelo público-alvo do questionário (MALHOTRA, 2012).

Os questionários foram respondidos pelos mesmos participantes da entrevista semiestruturada, onde foram elaboradas dez questões, sob o formato de afirmativas, e foram respondidas de forma individual. Acredita-se que esse grupo de participantes seja representativo no conjunto de funcionários da organização, dado a sua variedade de perfis e a capilaridade entre outras seções afins, o que garantiu o provimento de informações para que fosse alcançado os objetivos da pesquisa. O questionário que foi utilizado encontra-se no Apêndice A.

\section{Análise SWOT}

Após a realização das entrevistas e respostas do questionário, foi possível sistematizar os dados obtidos e as informações sobre a opinião do público-alvo da pesquisa diante de uma análise interna e externa de fatores. Para isso foi utilizada a ferramenta de análise denominada SWOT, do inglês Strengths; Weaknesses; Opportunities; Threats, que significam Forças; Fraquezas; Oportunidades; Ameaças, respectivamente.

Considera-se a análise SWOT uma ferramenta clássica na Administração, sendo muito útil para fazer análises de ambiente, servindo como base para a gestão e para o planejamento estratégico de todos os tipos de organização. É considerada um sistema de simples aplicação para o posicionamento ou verificação da posição estratégica da empresa no ambiente em questão (DAYCHOUW, 2007).

No caso da pesquisa, a referida ferramenta foi utilizada para se saber a opinião de militares acerca da implementação da gestão por processos no setor de compras, assim como o diagnóstico da situação atual em que a organização se encontra no assunto em questão.

Logo, diante das situações ideais e as situações reais possíveis, foi construída uma análise e diagnóstico tanto qualitativo, assim como quantitativo, visando fornecer uma abordagem mais ampla e completa dos processos de aquisições da organização 


\section{Apresentação e Discussão dos Resultados}

\section{Análise das questões abertas da pesquisa}

O Quadro 1 demonstra a classificação das principais atividades desenvolvidas entre os entrevistados, a função ocupada, o tempo de serviço e a formação acadêmica:

Quadro 1: Distribuição das funções, tempo na instituição e principais atividades desempenhadas

\begin{tabular}{|c|c|c|c|c|}
\hline PART. & FUNÇÃO OCUPADA & $\begin{array}{l}\text { FORMAÇÃO } \\
\text { ACADÊMICA }\end{array}$ & $\begin{array}{l}\text { TEMPO } \\
\text { DE } \\
\text { SERVIÇO }\end{array}$ & $\begin{array}{l}\text { PRINCIPAIS } \\
\text { ATIVIDADES } \\
\text { DESENVOLVIDAS }\end{array}$ \\
\hline 1 & Chefe do Setor de Aquisições & $\begin{array}{l}\text { Pós-Graduação em } \\
\text { Administração }\end{array}$ & 11 anos & $\begin{array}{l}\text { Coordenar ,fiscalizar e planejar as } \\
\text { atividades da seção de compras. }\end{array}$ \\
\hline 2 & $\begin{array}{l}\text { Chefe da Seção de } \\
\text { Licitações }\end{array}$ & $\begin{array}{l}\text { Nível superior, } \\
\text { curso de Direito }\end{array}$ & 18 anos & $\begin{array}{l}\text { Coordenação } \\
\text {,fiscalização e planejamento das } \\
\text { atividades da seção de licitações. }\end{array}$ \\
\hline 3 & $\begin{array}{l}\text { Chefe da Seção de } \\
\text { Conformidade e Registro de } \\
\text { Gestão }\end{array}$ & $\begin{array}{l}\text { Nível Superior, } \\
\text { curso de } \\
\text { Administração }\end{array}$ & 25 anos & $\begin{array}{l}\text { Conferência da conformidade de } \\
\text { todos os processos da organização } \\
\text { e registro de documentos. }\end{array}$ \\
\hline 4 & $\begin{array}{l}\text { Chefe da Divisão } \\
\text { Administrativa }\end{array}$ & $\begin{array}{l}\text { Pós-Graduação em } \\
\text { Contabilidade }\end{array}$ & 20 anos & $\begin{array}{l}\text { Controle do créditos e recursos } \\
\text { recebidos pela organização e } \\
\text { distribuição entre as unidades } \\
\text { subordinadas. }\end{array}$ \\
\hline 5 & $\begin{array}{l}\text { Adjunta da Seção de } \\
\text { Contratos }\end{array}$ & $\begin{array}{l}\text { Pós-Graduação } \\
\text { Strictu Sensu, } \\
\text { curso de Direito }\end{array}$ & 3 anos & $\begin{array}{l}\text { Controle dos contratos } \\
\text { continuados, contratos de receita, } \\
\text { solicitação de recursos para órgão } \\
\text { setoriais e controle de } \\
\text { fiscais de contrato } \\
\text { designados. }\end{array}$ \\
\hline 6 & $\begin{array}{l}\text { Auxiliar na Seção de } \\
\text { Empenhos }\end{array}$ & $\begin{array}{l}\text { Nível Superior, } \\
\text { curso de } \\
\text { Contabilidade }\end{array}$ & 17 anos & $\begin{array}{l}\text { Atividades do setor de emissão de } \\
\text { Notas de Empenho. }\end{array}$ \\
\hline 7 & $\begin{array}{l}\text { Auxiliar na Seção de } \\
\text { Empenhos }\end{array}$ & $\begin{array}{l}\text { Nível Superior, } \\
\text { curso de Direito }\end{array}$ & 15 anos & $\begin{array}{l}\text { Atividades do setor de emissão } \\
\text { de Notas de Empenho. }\end{array}$ \\
\hline 8 & $\begin{array}{l}\text { Pregoeiro e Membro } \\
\text { da Comissão } \\
\text { permanente de } \\
\text { licitações }\end{array}$ & $\begin{array}{l}\text { Nível Superior, } \\
\text { curso de Direito }\end{array}$ & 11 anos & $\begin{array}{l}\text { Atividades relativas aos } \\
\text { Pregões eletrônicos da } \\
\text { organização militar e } \\
\text { consultoria em } \\
\text { procedimentos de } \\
\text { licitações. }\end{array}$ \\
\hline 9 & $\begin{array}{l}\text { Auxiliar na Seção } \\
\text { de Empenhos e } \\
\text { Consultor de } \\
\text { Informática }\end{array}$ & $\begin{array}{l}\text { Nível Superior, } \\
\text { curso de } \\
\text { Contabilidade e } \\
\text { Nível Superior, } \\
\text { curso de } \\
\text { Informática }\end{array}$ & 4 anos & $\begin{array}{l}\text { Atividades do setor de emissão } \\
\text { de Notas de Empenho e } \\
\text { assessoria para assuntos de } \\
\text { tecnologia da informação (T.I). }\end{array}$ \\
\hline 10 & $\begin{array}{l}\text { Chefe da seção de } \\
\text { finanças de } \\
\text { organização militar } \\
\text { externa (principal } \\
\text { requisitante) }\end{array}$ & $\begin{array}{l}\text { Nível Superior, } \\
\text { curso de } \\
\text { Administração }\end{array}$ & 25 anos & $\begin{array}{l}\text { Administração geral sobre } \\
\text { aquisições, licitações e } \\
\text { contratos de sua Unidade; } \\
\text { Coordenar a execução } \\
\text { financeira dos créditos } \\
\text { destinados. }\end{array}$ \\
\hline
\end{tabular}

Fonte: Dados da pesquisa de campo, 2019.

Os recursos humanos que conduzem os processos no setor de aquisições da organização são qualificados, alguns com experiência de mais de vinte anos na Instituição, com vivência nacional em 
outras organizações similares, alguns com formação de pós-graduação e especialistas nos assuntos geridos pelo setor. Somado a isso, demonstram motivação na condução dos processos administrativos que são responsáveis, em função do bom ambiente de trabalho, que propicia um clima organizacional que gera a camaradagem e colaboração mútua entre os integrantes do setor.

A segunda questão analisada durante a pesquisa foi se a quantidade de servidores no setor de aquisições era adequada para o atendimento às necessidades da organização, onde foi registrado como sendo este, uma grande dificuldade devido à carência frequente de pessoal capacitado para desempenhar as funções pertinentes à atividade. Pode-se perceber como ponto em comum a todas as respostas obtidas, que o número de servidores envolvidos está longe de ser adequado às demandas, influenciando diretamente na qualidade do serviço prestado.

A figura 1 e a figura 2 mostram a quantidade de pregões realizados e a quantidade de emissões de notas de empenho (NE), respectivamente, desde o ano de 2005 ano de implantação da organização no Estado de Goiás, até o ano de 2018, onde foi feita uma análise em relação a quantidade de servidores trabalhando nestas duas funções específicas.

Figura 1: Quantitativo de pregões

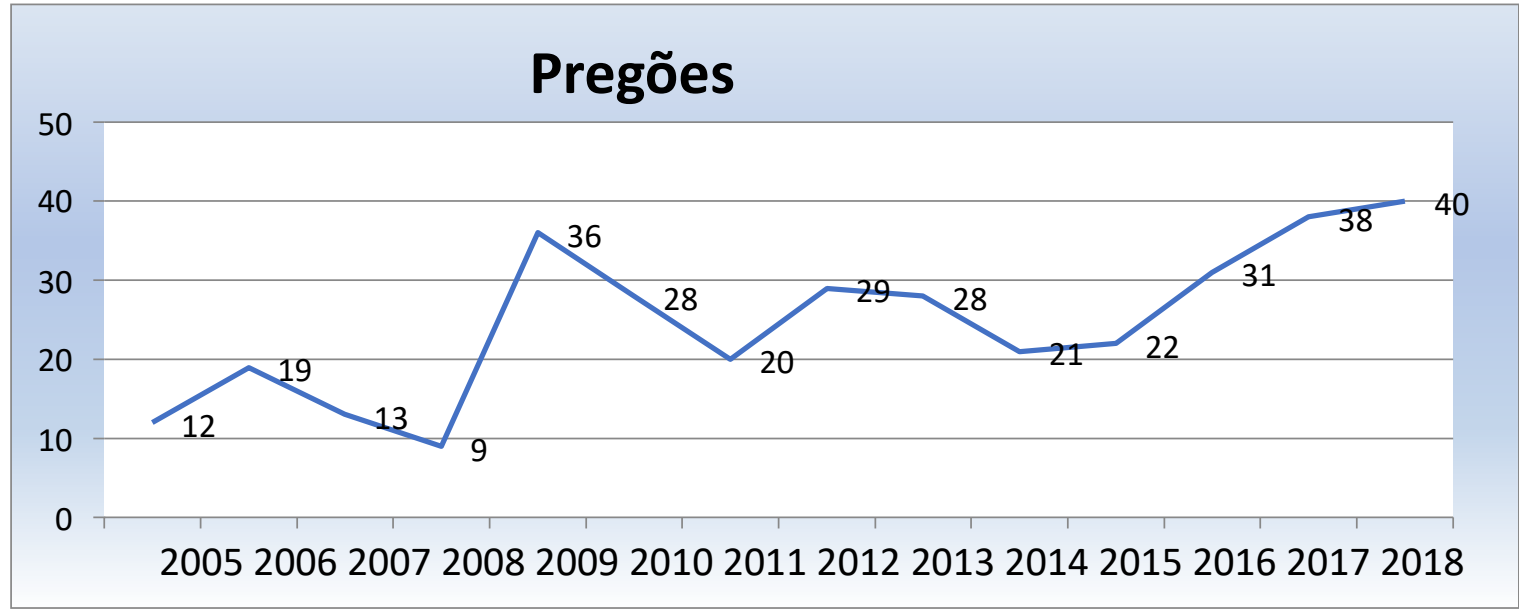

Fonte: Dados do site comprasgovernamentais.gov.br

Figura 2: Quantitativo de notas de empenho (NE) por ano

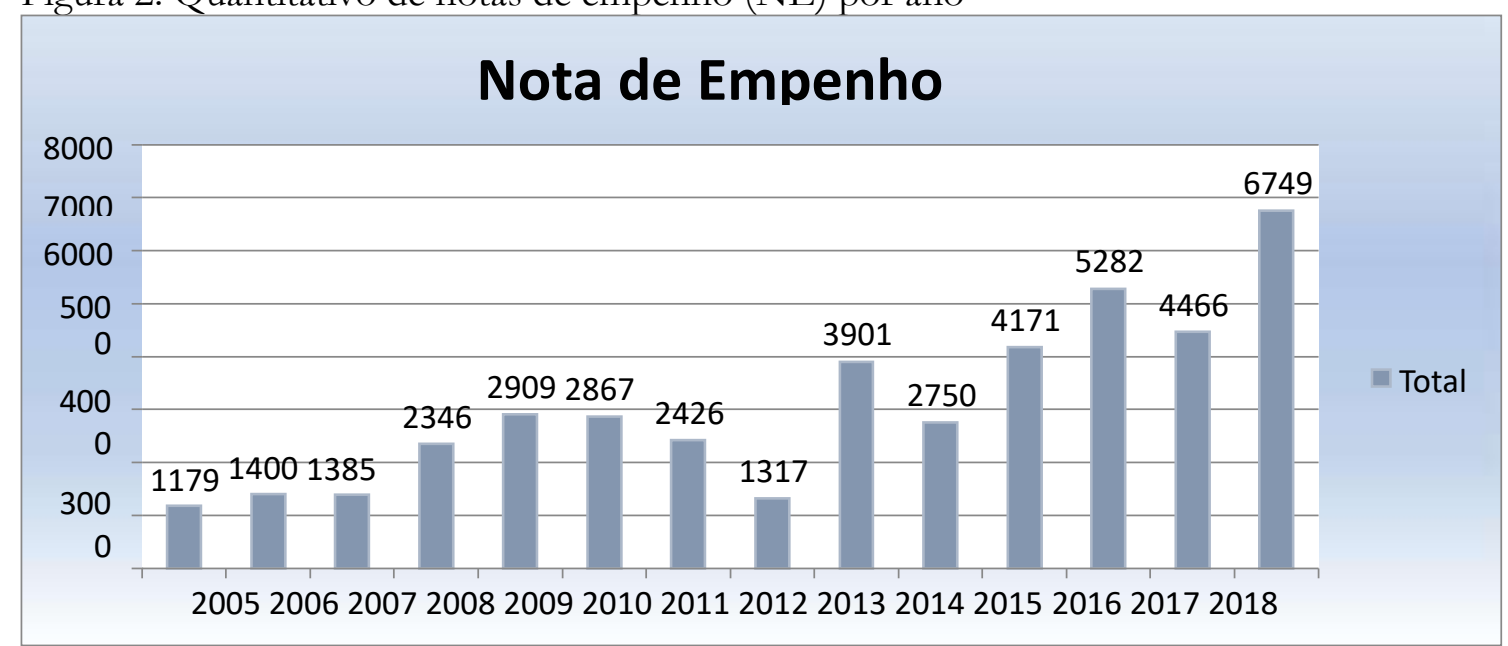

Fonte: Dados do sistema SIAFI (Sistema Integrado de Administração Financeira) operacional

Em função dos dados coletados e informações recebidas durante as perguntas da entrevista semiestruturada realizada, foi relatado pelos militares mais antigos e que já estão há mais tempo na 
Unidade, que desde a implantação da organização militar, se estabelecendo no Estado de Goiás, a quantidade de militares na função de pregoeiro não acompanhou o crescimento do volume de processos ao longo dos anos, oscilando entre três a cinco militares nesta carteira de trabalho específica, sendo um número aquém do volume de trabalho demandado, visto a crescente do número de pregões nos últimos anos, que culminou na maior quantidade já homologada no ano de 2018.

Acerca da carteira de trabalho responsável pela emissão de notas de empenho $(\mathrm{NE})$, o cenário fica ainda pior no quesito quantidade de militares trabalhando em função do aumento sensível no número de processos, constatando-se um significativo salto na demanda por esse tipo de serviço e assim como na carteira de trabalho de pregoeiros, a quantidade de militares envolvida nunca chegou a cinco, sendo um número muito inadequado, pois devemos sempre considerar que existem ainda os afastamentos temporários, sejam por férias, gravidez, a designação para alguma viagem ou curso, enfim, uma série de fatores contingenciais que podem sobrecarregar ainda mais a seção.

A terceira questão da pesquisa buscou conhecer se o setor de aquisições tem atendido as demandas das demais organizações que estão a ela vinculadas administrativamente, e no caso de não atender, quais seriam as oportunidades de melhoria.

Tabela 1 - Percentual de respostas positivas e negativas para atendimento das demandas

\begin{tabular}{|c|c|c|}
\hline RESPOSTA & QUANTIDADE & PORCENTAGEM \\
\hline Sim & 6 & $60 \%$ \\
\hline Não & 4 & $40 \%$ \\
\hline
\end{tabular}

Fonte: Dados da pesquisa de campo, 2019.

Constata-se com as respostas obtidas nesta questão e com o tabela 1 que é razoável estabelecer uma relação positiva entre o atendimento das solicitações por parte do setor de aquisições e as requisições enviadas, em função de que na maior parte dos pedidos, tem havido o atendimento da demanda, embora tenhamos algumas dificuldades na realização das atividades como a falta de um planejamento adequado para o uso dos recursos ao longo do exercício financeiro, gerando em virtude disso, um mal uso dos créditos destinados, arraigados por uma cultura de que devemos sempre utilizar na plenitude todos os recursos disponibilizados, sob pena de no ano seguinte termos uma diminuição do repasse feito por órgãos de direção setoriais, responsáveis pelo fracionamento entre as unidades gestoras subordinadas.

O quarto item da presente pesquisa buscou saber quais as modalidades de licitação que são utilizadas na organização. Em comum às respostas obtidas, foi verificado a modalidade Pregão, como sendo a mais utilizada, sendo ele no Sistema SRP (Sistema de Registro de Preços) o qual é utilizado em geral para aquisição de bens e contratação de serviços comuns.

A figura 3, corroborando com as respostas obtidas, mostra uma total predominância da referida modalidade, na sua forma eletrônica em relação às demais no ano de 2018 na Unidade Gestora (UG) e a tabela 2 mostra o valor empenhado dividido entre as modalidades. 
Figura 3 - Modalidades de licitações utilizadas.

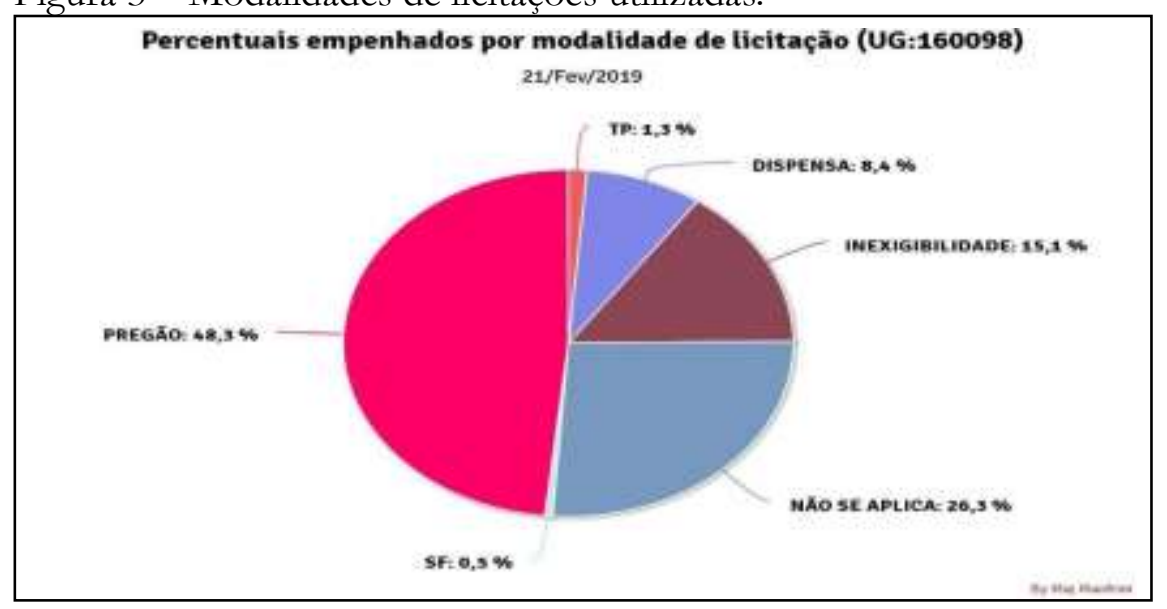

Fonte: Dados extraídos do SAG (Sistema de Acompanhamento e Gestão)

Tabela 2: Valor empenhado x modalidade

\begin{tabular}{|c|c|}
\hline MODALIDADE & MONTANTE (R\$) \\
\hline TOMADA DE PREÇOS (TP) & 397.123 \\
\hline DISPENSA & $2.470 .813,47$ \\
\hline INEXIGIBILIDADE & $4.440 .565,65$ \\
\hline NÃO SE APLICA & $7.739 .171,54$ \\
\hline SUPRIMENTO DE FUNDOS (SF) & $156.575,85$ \\
\hline PREGÃO & $14.224 .603,02$ \\
\hline TOTAL & $\mathbf{2 9 . 4 2 8 . 8 5 2 , 5 3}$
\end{tabular}

Fonte: Dados extraídos do SAG (Sistema de Acompanhamento e Gestão)

O próximo item da pesquisa é sobre a identificação de possíveis falhas no setor de aquisições e de como poderiam ser melhoradas, através de sugestões. Cabe aqui destacar como ponto em comum às respostas dos entrevistados falhas relacionadas à fase do planejamento das aquisições, prevalecendo uma intempestividade nas solicitações remetidas, sendo estes pedidos atrelados a disponibilização de recursos, ou seja, quando os recursos são disponibilizados, chegam os pedidos, sem que haja uma previsão quanto a isso, sendo que normalmente há uma escassez de tempo para a utilização do crédito, o que acarreta numa velocidade para o gasto que nem sempre é utilizado da melhor forma. Sendo assim, se houvesse um melhor planejamento, seja de curto, médio ou longo prazo, estaríamos mais preparados para se fazer uma análise e na sequência finalizar o pedido com maior eficiência.

O quadro 2 apresenta as falhas apontadas pelos entrevistados agrupadas conforme a sua recorrência entre as respostas dos entrevistados e as respectivas sugestões de melhorias. 
Quadro 2 - Falhas apontadas agrupadas conforme recorrência e sugestões de melhorias.

PARTICIPANTES FALHA APONTADA SUGESTÕES DE MELHORIAS

\begin{tabular}{|c|c|c|}
\hline $\begin{array}{l}\text { Quatro participantes } 1 ; 3 ; 4 \\
\quad \text { e } 9\end{array}$ & $\begin{array}{l}\text { Falta de um planejamento das } \\
\text { necessidades } \\
\text { baseados em um sistema de } \\
\text { medição orientado por } \\
\text { indicadores em relação às metas } \\
\text { estabelecidas }\end{array}$ & $\begin{array}{l}\text { Dar maior atenção à fase de planejamento com } \\
\text { mensuração de metas desempenhos e índices; } \\
\text { capacitação de pessoal externo ao setor no que } \\
\text { tange ao processo para a aquisição, de forma a } \\
\text { identificar melhor o objeto solicitado e as } \\
\text { características } \\
\text { padronização nos procedimentos em todas as } \\
\text { unidades. }\end{array}$ \\
\hline $\begin{array}{l}\text { Três participantes } 1 ; 4 \\
\text { e } 10\end{array}$ & $\begin{array}{l}\text { Falta comunicação entre o setor } \\
\text { de compras e as outras } \\
\text { unidades, } \\
\text { ocasionando uma demora na } \\
\text { velocidade de tomada de } \\
\text { decisões. }\end{array}$ & $\begin{array}{l}\text { Estabelecer um sistema de comunicação mais } \\
\text { eficiente entre os setores de compras de todos as } \\
\text { unidades, objetivando diminuir a quantidade de } \\
\text { processos e diminuição dos gargalos (pontos de } \\
\text { decisão em que o responsável não está disponível } \\
\text { para a tomada de decisões, na maioria das vezes) }\end{array}$ \\
\hline $\begin{array}{l}\text { Seis participantes } 1 ; 2 \\
5 ; 7 ; 8 \text { e } 10\end{array}$ & $\begin{array}{l}\text { Alta rotatividade de pessoal } \\
\text { ocasionando falta capacitação de } \\
\text { alguns servidores e um melhor } \\
\text { planejamento quanto às } \\
\text { necessidades. }\end{array}$ & $\begin{array}{l}\text { Diminuir a troca de função dos militares } \\
\text { envolvidos e viabilizar mais capacitação dos } \\
\text { servidores e, principalmente, com melhor } \\
\text { planejamento por parte da administração das } \\
\text { necessidades e demandas da organizações }\end{array}$ \\
\hline $\begin{array}{l}\text { Cinco participantes } 2 ; 3 \\
\quad 6 ; 7 \text { e } 9\end{array}$ & $\begin{array}{lr}\text { Falta capacitação de } & \text { militares } \\
\text { quanto à formalização } & \text { de } \\
\text { demandas nos } & \text { setores } \\
\text { requisitantes. } & \end{array}$ & $\begin{array}{l}\text { É preciso criar uma capacitação e padronização } \\
\text { sobre a elaboração de termos de referências, } \\
\text { atendendo principalmente os servidores } \\
\text { responsáveis pela formalização da demanda nos } \\
\text { setores, de forma a buscar esgotar todas as dúvidas } \\
\text { quanto ao objeto a ser adquirido. Deve-se } \\
\text { procurar, ainda, gerir os requisitos das partes } \\
\text { interessadas na aquisição de produto e contratação } \\
\text { de serviços por um colaborador designado. }\end{array}$ \\
\hline $\begin{array}{l}\text { Dois participantes } 2 \mathrm{e} \\
10\end{array}$ & $\begin{array}{l}\text { Falta relacionamento com os setores } \\
\text { solicitantes e melhoria dos pregões } \\
\text { de acordo com a demanda da } \\
\text { unidade. }\end{array}$ & $\begin{array}{l}\text { Realização de reuniões mensais com os setores } \\
\text { solicitantes, explanando sobre como funciona o } \\
\text { sistema de compras, de modo a reunir todas as } \\
\text { solicitações. Realização de licitação agregando itens } \\
\text { demandados pelos diferentes setores. }\end{array}$ \\
\hline $\begin{array}{l}\text { Três participantes } \\
1 ; 4 \text { e } 10\end{array}$ & $\begin{array}{l}\text { Falta um sistema de controle desde } \\
\text { o planejamento até a chegada do } \\
\text { produto ocasionando atraso nas } \\
\text { entregas. }\end{array}$ & $\begin{array}{l}\text { Elaboração um sistematica de controle efetiva desde } \\
\text { o planejamento, alimentando de dados a Licitação e } \\
\text { Compras e que permita o acompanhamento pelo } \\
\text { Almoxarifado. }\end{array}$ \\
\hline
\end{tabular}

Fonte: Dados da pesquisa de campo, 2019.

Conforme apresentado no quadro 2, observa-se que existem muitos fatores que necessitam de melhorias, nesse sentido, de acordo com os objetivos da pesquisa, destacam-se os apontados pelos participantes 6; 9 e 10, pois estão alinhados com os princípios da gestão por processos e se atendidos em suas respectivas sugestões, alavancariam os resultados da organização, contribuindo para serem alcançados os resultados esperados. Sugestão do participante 6: criação da figura do militar que será o responsável designado como o dono do processo; sugestão do participante 9: adaptações para equipes interfuncionais, onde o trabalho em equipe deve ser incentivado dentro do setor de compras, buscando uma maior integração entre as pessoas; sugestão do participante 10: incentivo para haver uma maior participação de todos da organização através da utilização de sugestões via Intranet, independentemente da posição, função ou grau hierárquico ocupado.

Diante das respostas obtidas nas questões 3 e 5 , podemos identificar os pontos fortes, pontos fracos no ambiente interno, assim como as oportunidades e ameaças analisando-se o ambiente externo, através de uma Matriz SWOT (Strengths, Weaknesses, Opportunities e Threats), levando-se em 
consideração as circunstâncias ideais e as circunstâncias reais admissíveis.

A pesquisa buscou conhecer também se uma mudança na forma como são conduzidos os processos intraorganizacionais seria possível e efetivamente aplicável à instituição, além de questionar se estaria disposto a aceitar e participar da mudança.

Através da impressão obtida das experiências dos entrevistados, percebe-se que temos dois pontos distintos sob a ótica da questão: o ponto de vista dos que acreditam e acham possível uma mudança e a das pessoas que gostariam de que fosse mudado o rumo dos trâmites processuais, entretanto tem dúvida quanto a fase de implementação na organização, se seria viável tal transformação, dado as limitações encontradas numa instituição verticalizada. Quanto ao questionamento sobre a aceitação de uma eventual mudança, todos se mostraram dispostos a fazer parte da transição.

Diante dos dados encontrados, destacam-se os obstáculos à mudança relacionados pelos entrevistados: Dificuldade na prática de trabalhos em equipe, devido a estrutura fortemente hierarquizada e departamentalizada, como é o caso de uma organização militar; há uma delegação de poder insuficiente, com grande centralização das decisões; falta de priorização da gestão por processos por parte da autoridade competente, pois para se haver uma gestão de mudanças, faz-se necessário o envolvimento da direção e chefia; a alta rotatividade de pessoal nas funções, onde os militares são substituídos, porém os que chegam não passam por um treinamento adequado; e o excesso de rotinas, o que acaba por desmotivar o militar para a sequência do processo.

Portanto, o conflito criativo de forma alguma se opõe aos princípios basilares de hierarquia e disciplina. As ideias e opiniões trazidas à baila são submetidas ao crivo do líder, que, em última instância, será quem dará o parecer final, sendo realmente relevante para o bom líder, o reconhecimento das melhores sugestões e colocá-las em prática, independente de quem a possa ter gerado.

A última pergunta da entrevista semiestruturada realizada foi se o militar envolvido se sentiria mais valorizado e reconhecido pela instituição ao fazer parte da mudança, ainda que para isso ocorrer, aumente também a sua responsabilidade.

De acordo com as respostas da questão sete, é possível concluir que todos se sentiriam mais valorizados e reconhecidos, buscando a motivação e o compartilhamento das responsabilidades envolvidas, porém se mostraram receosos com a situação de ter um aumento de responsabilidade, dado o alto volume de trabalho já existente e se haveria o compromisso de todos os integrantes da cadeia de aquisições. Todavia, este pesquisador pode perceber que cerca da metade dos militares entrevistados se mostraram preocupados com o aumento específico de atribuições na sua carteira de trabalho, estando voltado para o seu trabalho individualmente, e nem tanto com novos desafios que uma mudança no rumo dos processos necessitaria. Sendo este fato comum às respostas percebido como resistência, encontrado entre os militares com mais tempo de serviço, evidenciando que os mais novos e com menos tempo de serviço se mostraram mais suscetíveis às mudanças e as inovações a serem implementadas. A quebra de alguns de paradigma, será um dos grandes desafios para a implementação da filosofia de gestão por processos.

\section{Análise das questões fechadas da pesquisa}

O questionário foi elaborado mediante utilização da escala de Likert e conta com 10 afirmações que foram pontuadas de 1 a 5 (discordo plenamente a concordo plenamente). Analisa-se a seguir as expectativas dos entrevistados acerca das etapas que antecedem a implementação da gestão por processos, sendo divididas em três blocos: aquele referente ao mapeamento a ser realizado, referente ao redesenho que será consequência do referido mapeamento e, finalizando, a seção referente as adaptações necessárias à estrutura da organização militar na forma como os processos tramitam. 


\section{Análise dos dados referentes ao mapeamento a ser realizado}

Sobre a análise dos dados referentes ao mapeamento a ser realizado considerou-se inicialmente as afirmativas individuais, visando obter-se uma melhor compreensão das atividades a serem implementadas eventualmente.

Tabela 3: Afirmativas relacionadas à etapa do mapeamento de processos a ser realizado

\begin{tabular}{lc}
\multicolumn{1}{c}{ Afirmativas } & Moda de Notas \\
\hline 8. O mapeamento a ser realizado irá melhorar os processos existentes & 5,0 \\
\hline $\begin{array}{l}\text { 9. As entrevistas da presente pesquisa foram eficazes para coleta de informações sobre o } \\
\text { assunto. }\end{array}$ & 5,0 \\
\hline $\begin{array}{l}\text { 10. Os funcionários visualizariam de maneira mais fácil suas atividades após o } \\
\text { mapeamento. }\end{array}$ & 4,0 \\
\hline Fonte: Dados da pesquisa de campo, 2019.
\end{tabular}

Depois das análises individuais das afirmativas, o bloco sobre o mapeamento a ser realizado foi analisado em sua totalidade, apresentando a moda geral e a moda das notas dos entrevistados, respectivamente, dispostas na tabela 4 . A fase de mapeamento a ser realizado é imprescindível para a mudança a ser implementada na organização militar, e foi verificado que essa etapa está gerando uma excelente impressão, apresentando uma moda geral de 5,0; como é mostrado na tabela.

Tabela 4: Notas atribuídas à etapa correspondente ao mapeamento a ser realizado

\begin{tabular}{ccccc}
\hline Afirmativas & 8 & 9 & 10 & $\begin{array}{c}\text { Moda por } \\
\text { entrevistado }\end{array}$ \\
\hline Entrevistados & Notas & Notas & Notas & Notas \\
\hline 1 & 5,0 & 5,0 & 5,0 & 5,0 \\
2 & 4,0 & 5,0 & 4,0 & 4,0 \\
\hline 3 & 4,0 & 4,0 & 4,0 & 4,0 \\
4 & 5,0 & 5,0 & 5,0 & 5,0 \\
5 & 5,0 & 5,0 & 4,0 & 5,0 \\
6 & 5,0 & 5,0 & 3,0 & 4,0 \\
7 & 4,0 & 4,0 & 3,0 & 4,0 \\
8 & 5,0 & 4,0 & 4,0 & 5,0 \\
\hline 1 & 4,0 & 5,0 & 5,0 & Não há moda \\
(Amodal)
\end{tabular}

Fonte: Dados da Pesquisa de Campo, 2019.

\section{Análise dos dados referentes ao redesenho de processos de trabalho}

Assim como no bloco de afirmativas anterior, inicialmente também serão mostrados os resultados das afirmativas individuais. 
Tabela 5: Afirmativas relacionadas à etapa de redesenho de processos de trabalho

\begin{tabular}{lc}
\multicolumn{1}{c}{ Afirmativas } & Moda de Notas \\
$\begin{array}{l}\text { 11. Os processos redesenhados facilitariam a comunicação entre as } \\
\text { áreas. }\end{array}$ & 2,0 \\
\hline $\begin{array}{l}\text { 12. As modificações a serem propostas pelo redesenho nas rotinas de trabalho } \\
\text { seriam bem aceitas pelos funcionários. }\end{array}$ & 3,0 \\
\hline $\begin{array}{l}\text { 13. Os processos que apresentam problemas como o retrabalho, excesso de } \\
\text { tramitação, entre outros seriam solucionados após o redesenho. }\end{array}$ & 4,0 \\
\hline
\end{tabular}

Fonte: Dados da pesquisa de campo, 2019.

As análises individuais das afirmativas apontam que não necessariamente a melhora da comunicação entre as áreas está atrelada ao redesenho de processos de trabalho, fato este que corrobora com a análise de contexto que sobre a comunicação entre os interessados, seria mais relevante aperfeiçoar os meios já disponíveis do que realizar um redesenho do processo sobre o assunto. Ressalta-se que a afirmativa 11 foi a que apresentou a moda menor atribuída dentre todas da presente pesquisa nos três blocos analisados.

Tabela 6: Notas atribuídas à etapa correspondente ao redesenho de processos de trabalho

\begin{tabular}{|c|cccc|}
\hline Afirmativas & 11 & 12 & 13 & $\begin{array}{c}\text { Moda por } \\
\text { entrevistado }\end{array}$ \\
\hline Entrevistados & Notas & Notas & Notas & Notas \\
\hline 1 & 5,0 & 4,0 & 4,0 & 4,0 \\
2 & 5,0 & 5,0 & 4,0 & 5,0 \\
\hline 3 & 5,0 & 4,0 & 4,0 & 4,0 \\
\hline 4 & 4,0 & 4,0 & 4,0 & 4,0 \\
\hline 5 & 3,0 & 3,0 & 4,0 & 3,0 \\
\hline 6 & 3,0 & 3,0 & 3,0 & 3,0 \\
\hline 7 & 2,0 & 3,0 & 3,0 & 3,0 \\
\hline 8 & 2,0 & 5,0 & 5,0 & 5,0 \\
\hline 9 & 2,0 & 5,0 & 5,0 & 5,0 \\
\hline 1 & 2,0 & 3,0 & 3,0 & 3,0 \\
\hline Moda por afirmativa & 2,0 & 3,0 & 4,0 & 3,0 \\
\hline
\end{tabular}

Fonte: Dados da pesquisa de campo, 2019.

Então, a opinião dos militares sobre a etapa de redesenho, não apresentou uma moda geral predominante, com modas apresentadas de 2; 3 e 4; onde observa-se uma queda em relação a análise do bloco anterior, já apresentando alguns sinais de discórdia ou indiferença nas respostas da pesquisa, sendo ratificado pela moda geral por entrevistado, com nota de 3,0; o que demonstra que uma mudança no rumo do gerenciamento dos processos é uma etapa que apresenta algumas barreiras ao longo do caminho, devido a sua natural complexidade na atual conjuntura. 


\section{Análise dos dados referente às adaptações na estrutura organizacional}

O bloco da pesquisa relativa à estrutura organizacional trouxe questões que focalizam a compreensão dos militares acerca das adaptações da forma como vão ser movimentados os processos, pois o que será assessorado para os chefes tomarem a decisão será adaptar uma estrutura departamental/funcional, que é a situação atual, para uma organização orientada por processos, fazendo com que haja uma estrutura híbrida e não uma estrutura matricial. Prosseguindo com o mesmo método de análise e apresentação, foram analisadas as afirmativas individuais, como maneira de se verificar as características das mudanças a serem sugeridas.

Tabela 7: Afirmativas relacionadas às adaptações na estrutura organizacional

14. A estrutura organizacional adaptada após o redesenho dos processos mudaria para melhor.

3,0

15. A realocação de militares para funções distintas das atuais seria benéfico para a organização.

Bimodal $(3,0$ e 5,0$)$

16. O conflito de interesses entre as áreas seria reduzido.

17. A tramitação dos processos entre as áreas ficaria mais ágil.

5,0

5,0

Fonte: Dados da pesquisa de campo, 2019

Após as análises individuais, a seção foi analisada de forma geral, apresentando a moda de notas dos participantes e a moda geral, conforme tabela abaixo relacionada:

Tabela 8: Notas atribuídas à seção correspondente às adaptações na estrutura organizacional

\begin{tabular}{|cccccc|}
\hline Afirmativas & 14 & 15 & 16 & 17 & Moda por entrevistado \\
\hline Entrevistados & Notas & Notas & Notas & Notas & Notas \\
\hline 1 & 4,0 & 4,0 & 5,0 & 4,0 & 4,0 \\
2 & 4,0 & 5,0 & 5,0 & 5,0 & 5,0 \\
\hline 3 & 3,0 & 5,0 & 5,0 & 5,0 & 5,0 \\
\hline 4 & 4,0 & 5,0 & 4,0 & 5,0 & Bimodal $(4,0$ e 5,0$)$ \\
\hline 5 & 3,0 & 4,0 & 4,0 & 4,0 & 4,0 \\
\hline 6 & 3,0 & 3,0 & 5,0 & 4,0 & 3,0 \\
\hline 7 & 3,0 & 3,0 & 3,0 & 5,0 & 3,0 \\
\hline 8 & 3,0 & 3,0 & 3,0 & 4,0 & 2,0 \\
\hline 9 & 2,0 & 2,0 & 4,0 & 5,0 & 2,0 \\
\hline 10 & 2,0 & 2,0 & 3,0 & 5,0 & 3,0 \\
\hline Moda por afirmativa & 3,0 & Bimodal & 5,0 & 5,0 & \\
\hline
\end{tabular}

Fonte: Dados da pesquisa de campo, 2019.

O bloco correspondente às adaptações na estrutura organizacional apresentou uma moda final de 5,0; que em comparação com a etapa de redesenho apresentou uma sensível melhora, igualando a moda final do bloco sobre o mapeamento, cabendo destacar que em relação aos demais blocos de afirmativas, este contava com uma assertiva a mais, sendo observado algumas dúvidas quanto a implementação devido à forte cadeia hierárquica de comando, marcante em uma organização militar, conforme observado com modas finais por entrevistado iguais a 2,0, fato este que não foi verificado em nenhum dos outros dois blocos, mas ainda assim, buscando a quebra de antigos conceitos, como pode ser percebido com a moda final do bloco. 


\section{Análise final dos dados conforme escala Likert}

Os três blocos divididos entre os assuntos com suas respectivas afirmativas receberam, de maneira geral, notas muito boas aplicadas mediante utilização da escala Likert, o que gera uma moda geral da pesquisa entre muito boa e excelente, de acordo com a tabela 9 a seguir:

Tabela 9: Moda geral das notas por participante da pesquisa

\begin{tabular}{|c|c|c|c|c|c|c|c|c|c|c|}
\hline \multicolumn{11}{|c|}{ MODA GERAL POR PARTICIPANTE } \\
\hline Entrevistados & 1 & 2 & 3 & 4 & 5 & 6 & 7 & 8 & 9 & 10 \\
\hline $\begin{array}{l}\text { Moda de notas } \\
\text { por entrevistado }\end{array}$ & $\begin{array}{l}\text { Bimodal } \\
\quad(4 \text { e } 5)\end{array}$ & 5,0 & 4,0 & $\begin{array}{l}\text { Bimodal } \\
(4 \text { e } 5)\end{array}$ & 4,0 & 3,0 & 3,0 & $\begin{array}{l}\text { Trimodal } \\
(3 ; 4 \text { e } 5)\end{array}$ & 5,0 & 3,0 \\
\hline
\end{tabular}

Fonte: Dados da Pesquisa de Campo, 2019.

Logo, como ponto em comum, entre as maiores notas pode-se observar que foram entre os chefes de seções, demonstrando que, mesmo não sendo de forma muito expressiva, as opiniões dos subordinados e seus chefes imediatos se apresentam destoantes, fato este que pode revelar um certo grau de influência do nível estrutural da organizacional militar sobre a opinião dos participantes, mesmo que não seja de forma tão marcante, pois diante de uma moda geral final de 5,0 entre todos os participantes sobre as dez afirmativas, evidenciamos que o trabalho a ser desenvolvido conta com o apoio e tem gerado uma grande expectativa em uma parcela da organização militar.

Portanto, partindo da premissa de que os dados, quando tratados e analisados corretamente, transformam-se em informações importantes para os ambientes organizacionais diante de técnicas de estatísticas, contribuindo para a tomada de decisão, baseado no conhecimento adquirido (FÁVERO, L.P.; BELFIORE, P., 2017), de forma geral, a maioria dos participantes apresentaram argumentos positivos para a implementação da prática de gestão por processos. Sendo assim, a nova orientação, caso seja colocada em prática, foi avaliada pela maioria dos entrevistados como uma boa experiência de gestão, seja devido à redução de tempos e custos, seja pela modernização da gestão, acompanhando a evolução das organizações ou pelo fato de auxiliar para que ocorra um melhor planejamento, fatores que encontram respaldo na literatura sobre o assunto.

\section{Considerações Finais}

Diante da realização da pesquisa de campo, através da entrevista semiestruturada e o questionário baseado na escala Likert, assim como observações deste pesquisador, em função dos objetivos propostos no trabalho, conclui-se que o setor de compras da organização militar possui falhas e dificuldades a serem superadas ou resolvidas através de um melhor planejamento e a elaboração e divulgação de planos de ação, entretanto evidenciou a alta expectativa e muito boa receptividade por parte dos entrevistados, acerca das mudanças a serem propostas para implementação de uma nova forma para a orientação por processos.

Entre as principais oportunidades de melhoria e obstáculos registrados na pesquisa, destacamse a comunicação ineficiente entre o setor de compras e as outras unidades requisitantes; e o excesso de burocracia nos procedimentos para as aquisições.

Constata-se que as disfunções da burocracia nos processos de compra vem sendo um dos fatores que atrapalham o bom andamento para a rapidez e alcance das necessidades, entretanto, por se tratar de uma organização militar, é uma característica que se faz necessário tornando-se imprescindível, não sendo possível a sua retirada do processo em função das legislações vigentes.

Em decorrência da pesquisa realizada é possível a sugestão de algumas iniciativas imediatas para a implementação da gestão por processos. A princípio, a criação de células de planejamento 
espalhadas entre as organizações que expedem requisições, de forma que através da troca de informações entre elas geradas através do debate, tenha-se uma uniformidade nas demandas, com criações de procedimentos operacionais padrão, de forma que haja uma diminuição entre as disparidades encontradas, sejam elas de especificação de um material ou uma cotação eletrônica, fazse pertinente.

Outra proposta a ser avaliada será o assessoramento para a contratação de uma empresa especializada para que seja realizado o mapeamento dos processos existentes, assim como já fizeram outras organizações militares que podem servir de referência, tais como a Academia Militar das Agulhas Negras (AMAN); a Diretoria de Fiscalização de Produtos Controlados (DFPC) e o Hospital Central do Exército (HCE).

Reitera-se a elevada média final das notas sobre o mapeamento a ser realizado; diagnóstico e redesenho e às adaptações na estrutura organizacional, nas respostas obtidas com as perguntas fechadas, evidenciando que de maneira geral, os funcionários estão dispostos à mudança e estão com alta expectativa para sua implementação. O que se espera através do referido mapeamento a ser realizado, será o diagnóstico e redesenho dos processos, uma vez que a organização que não mede e não controla seus processos, não gerencia e, consequentemente, fica sem parâmetro para se buscar uma melhora.

Embora uma unidade militar esteja diante da égide da hierarquia e a disciplina, estes não devem ser considerados fatores que limitem a atuação dos integrantes da seção de aquisições em uma organização voltada para conceitos da gestão por processos, eles apenas balizam o comprometimento e intensificam a responsabilidade atribuída a cada funcionário. Onde se a autoridade competente se conscientizar da necessidade de mudança, existe espaço para autonomia conferida pelo chefe da seção, em função do nível de conhecimento e qualificação dos profissionais e da liderança exercida na condução das tarefas, estimulando a proatividade para desenvolver melhores atributos profissionais.

Diante desse cenário, com uma cadeia de comando muito marcante e com alto grau de amplitude de controle e centralização das decisões, somados a valores arraigados ao militar ao longo da carreira, a quebra de paradigmas é um fator que pode se constituir num aspecto limitador para prática da gestão por processos, no entanto, na seção de aquisições da organização militar que foi objeto da pesquisa, o ambiente de trabalho, a cultura e os valores compartilhados corroboram para o empenho dos seus integrantes na execução das missões. Todavia, admite-se que em outras circunstâncias podem se constituir em fatores de limitação. Sendo assim, recomenda-se para continuidade deste presente trabalho a realização de um estudo de caso que avalie a característica da cadeia de comando para a gestão por processos em outras organizações militares.

Outro fator de limitação desta pesquisa foi a inexistência de documentos e relatórios de controle interno da organização estudada que respaldasse a análise dos dados levantados. Pois embora a análise seja feita por meio da percepção dos militares sobre o trabalho desenvolvido e expectativa para mudanças, os documentos auxiliares, como relatórios sobre avaliações de controle, indicadores de desempenho, entre outros, teriam papel importante, agregando valor e informações para a presente pesquisa.

Portanto, considerando a organização como um organismo vivo, sendo um sistema aberto composto por vários órgãos MORGAN (2002), e necessitando que todos estejam funcionando em perfeita sintonia de acordo também com os diversos vetores nos dias de hoje, tais como a transparência na utilização de recursos, parcimônia e eficácia nos gastos públicos, desenvolvimento sustentável, austeridade, probidade, entre outros; para o bom andamento dos processos, faz-se necessário a implementação de mudanças, pois com o aprimoramento e a aplicação de técnicas de modernização para a organização com as informações levantadas por esse e, eventualmente por estudos semelhantes, podem originar instituições mais aptas a atender as necessidades de seu público alvo, provocando uma maior satisfação diante da população em relação às organizações públicas, de forma que sejam respeitadas a nossa cultura e que mantenhamos nossos valores, porém agora, com novos desafio. 


\section{Referências}

ALMEIDA, D. A.; FAGUNDES, L. D. Aplicação do Modelo do Conhecimento de Cinco Fases para Reduzir Perdas em Concessionárias de Energia Elétrica. PRODUTO \& PRODUÇÃO, VOL. 8, N. 3, P. 63-79, OUT. 2005.

BPM CBOK - Guia para o Gerenciamento de Processos de Negócio. Corpo Comum do Conhecimento - ABPMP BPM CBOK V3.0, Association of Business Process Management Professionals, 2013.

DAYCHOUW, M. 40 Ferramentas e Técnicas de Gerenciamento. $3^{a}$ ed. Rio de Janeiro: Brasport, 2007. DINSMORE, P.; CABANIS-BREWIN, J. AMA: manual de gerenciamento de projetos. Rio de Janeiro: Brasport, 2009.

DREYFUSS, Caccio. As redes de gestão das organizações. Rio de Janeiro: Guide, 1996.

FÁVERO, L.P.; BELFIORE, P. Manual de análise de dados: Estatística e modelagem multivariada com Excel, SPSS e Stata. Rio de Janeiro: Elsevier, 2017.

GIL, A. C. Métodos e técnicas em pesquisa social. 6. ed. São Paulo: Atlas, 2008.

GONÇALVES, J. E. L. As Empresas são Grandes Coleções de Processos. RAE - Revista de Administração de empresas jan/mar 2000 São Paulo, v.40 nº 01, 2000.

HAMMER, M., STANT0N, S. How process enter price really work. Harvard Business Review, w. 77, n. 6, p. 108-118, Nov./Dec. 1999

LEAL, F; PINHO, A. F.; ALMEIDA, D. A. Análise de Falhas Através da Aplicação do Fmea e da Teoria Grey. Dissertação (Mestrado), Fundação Getúlio Vargas, Curso de Mestrado em Administração Pública, Rio de Janeiro, 2008.Acessado em 20 dez 18.

MALHOTRA, N. Pesquisa de Marketing: Uma orientação aplicada. $4^{a}$ ed. Rio Grande do Sul: ARTMED Editora, 2004.

MANZINI, E. J. A entrevista na pesquisa social. Didática, São Paulo, v. 26/27, p. 149-158, 1990/1991.

MORGAN, G. Imagens da organização. São Paulo: Atlas, 2002.

OLIVEIRA, D. R. Planejamento estratégico: conceitos, metodologia e práticas. 24.ed. São Paulo: Atlas, 2007.

RADUCNIZER, M. Gestão por Processos: 5 passos para o sucesso e algumas armadilhas. 2008. Disponível em: http://www.administradores.com.br/noticias/administracao- e- negocios/gestaopor-processos-5-passos-para-o-sucesso-e-algumas-armadilhas/15750/. Acesso em 20 nov.,18.

SILVA, J. G. Gestão por processos em organizações públicas: uma análise sobre obstrutores e facilitadores do mapeamento de processo em organizações públicas 2014.

TERRA, A. C. P. Compras públicas inteligentes: um modelo de análise estratégica para a gestão das compras públicas - estudo de caso do instituto do meio ambiente e dos recursos hídricos do distrito federal. Dissertação (Mestrado em Administração Pública). Universidade Federal de Goiás. Goiânia, 2016. Acesso em 10 out 18.

VINHEIROS, P. C. A Contribuição da Gestão por Processos nas Compras Governamentais. Disponível em: http://www.ecg.tce.rj.gov.br/arquivos/08CIPAD_ VinheirosPricilla.pdf. 2008. Acesso em 5 out 18 .

YIN, R. Estudo de caso: planejamento e métodos. 3. ed. Bookman: Porto Alegre, 2005. 